\title{
RIO 2016 E OS LEGADOS DE ESPORTE DE LAZER ${ }^{1}$
}

Recebido em: $12 / 12 / 2013$

Aceito em: 17/04/2014

\author{
Katiuscia Mello Figuerôa ${ }^{2}$ \\ Fernando Marinho Mezzadri ${ }^{3}$ \\ Marcelo Moraes e Silva ${ }^{4}$ \\ Universidade Federal do Paraná \\ Curitiba - PR - Brasil
}

RESUMO: O objetivo do estudo é fazer um acompanhamento das relações entre as propostas para o esporte de lazer, inseridas no Dossiê de Candidatura e nos Cadernos de Legados dos Jogos Olímpicos e Paralímpicos Rio 2016, com o planejamento, ações e financiamento para a área durante a fase inicial de construção dos legados esportivos. A pesquisa tem caráter qualitativo e utiliza como instrumentos a análise documental e entrevistas abertas. Concluiu-se que, por enquanto, os olhares estão voltados principalmente para as promessas de entrega de infraestrutura, no que se refere à realização dos jogos e ao desenvolvimento do esporte de alto rendimento. As questões sobre o esporte de lazer vão sendo postergadas, correndo-se o risco de não se desenvolverem.

PALAVRAS CHAVE: Atividades de lazer. Esportes. Políticas Públicas.

\section{RIO 2016 LEGACY OF SPORT AND LEISURE}

ABSTRACT: The main objective of this research is to accompany the relationship between the proposals for the leisure sport in the Candidature Dossier and the Legacy Brochure of the Olympic and Paralympic Games Rio 2016 with the planning, actions and funding of the area during the initial stage of sporting legacies' construction. The study has qualitative aspect and uses the documental analyses and open interviews as tools. The conclusion is that, meanwhile, the gaze is basically directed to the promises about delivery of infrastructures for the execution of the games and to the development

\footnotetext{
${ }^{1}$ O presente trabalho conta com o financiamento do Programa Nacional de Pós-Doutorado Institucional PNPD Institucional, da Fundação Coordenação de Aperfeiçoamento de Pessoal de Nível Superior CAPES.

${ }^{2}$ Pós-Doutoranda em Educação Física UFPR/Curitiba/PR/Brasil.

${ }^{3}$ Professor do Programa de Pós-Graduação em Educação Física da UFPR.

${ }^{4}$ Pós-Doutorando em Educação Física UFPR/Curitiba/PR/Brasil.
} 
of high performance sport. The matters linked to the leisure sports are being postponed at the risk of do not have an improvement.

KEYWORDS: Leisure Activities. Sports. Public Policies.

\section{Introdução}

Desde 2003, quando se constituiu o Ministério do Esporte (ME), o esporte brasileiro passou a fazer parte do $1^{\circ}$ escalão do governo brasileiro. Através de uma pasta própria, o esporte passou a ser tratado de forma diferenciada, entrando na agenda prioritária do Governo Federal (GF), com isso instituíram-se várias políticas públicas que se materializaram em diversos programas, projetos e ações.

A organização interna do ME encontra-se hoje dividida em secretarias específicas, que compreendem o esporte em três dimensões: rendimento, que faz parte da Secretaria Nacional de Esporte de Alto Rendimento (SNEAR); educacional e de lazer, ambos alocados na Secretaria Nacional de Esporte, Educação, Lazer e Inclusão Social (SNELIS). Além disso, criou-se em 2011 uma secretaria exclusiva para assuntos relacionados ao futebol, a denominada Secretaria Nacional de Futebol e Defesa do Torcedor (SNFDT).

Enfatizando nesse momento o esporte de lazer, também denominado de participativo ou recreativo, vale lembrar que a promulgação da Constituição Federal (CF) de 1988 foi um importante marco social e político no país, já que essa manifestação foi reconhecida formalmente no artigo $6^{\circ}$ como um direito social. Gomes e Pinto (2009) esclarecem que a CF tratou de questões complexas e que a conquista plena dos direitos previstos está distante da realidade da maioria da população, mas o reconhecimento do lazer como um direito social foi uma grande conquista. 
Menicucci (2008) afirma que o conceito de lazer tem sido definido de diferentes formas e se associa a distintos conteúdos, o que dificulta a definição do alvo de uma política pública voltada para a garantia desse direito. Dessa forma, estudos e pesquisas podem fornecer subsídios importantes para esse campo da ação governamental, dando mais visibilidade àquilo que está sendo feito, bem como às concepções que informam as escolhas políticas.

O estudo de Reis e Sousa-Mast (2012) afirma que o conhecimento acadêmico sobre os legados esportivos é extremamente escasso. Apesar de haver um crescimento no número de trabalhos sobre a temática, Souza e Pappous (2013) lembram que as produções versam basicamente sobre os legados econômicos e/ou sociais. Ao seguir a esteira destas argumentações e relacioná-las com o legado dos Jogos Olímpicos e Paralímpicos (JO/PO) 2016, percebe-se que, nos comentários sobre a temática no Brasil, quase sempre são enfatizadas suas questões adversas (OURIQUES, 2009; MASCARENHAS, 2012; ATHAYDE, et. al., 2013). Nesse sentido, há uma demanda de mais produção na área, para que as oportunidades que visam ao aumento da participação no esporte, através da realização dos JO/PO, sejam maximizadas e não préconcebidas. Para Filgueira (2008), esse assunto deve pressupor instâncias próprias, capazes de assegurar a prioridade que o tema requer em todo o processo, isto é, antes, durante e depois dos jogos. Na fase inicial, conceituando e dimensionando os legados, no planejamento e organização; tratando de tarefas de idealização daqueles; e, finalmente, após a realização do evento, abordando a gestão e administração dos legados. O autor ainda ressalta a necessidade de envolvimento da sociedade no processo, pois somente dessa forma é possível garantir um legado voltado para o social, bem como para o seu futuro uso e incorporação. 
Nesse sentido, o presente artigo pretende realizar uma "policy analyses", buscando analisar o planejamento e as ações das políticas públicas implementadas pelo GF para o esporte de lazer, pensando, principalmente, suas relações com as propostas inseridas no Dossiê de Candidatura (DC) e nos Cadernos de Legados (CLs) dos JO/PO de 2016.

\section{Marco teórico}

No Brasil, o termo "política" possui uma terminologia abrangente, constituído pelas instituições (partidos políticos e órgãos governamentais), pelos agentes (políticos e gestores) e pelo desenvolvimento das ações (programa e projetos); ou seja, engloba todas as dimensões possíveis do ato de governar. Porém, Frey (2000), ao delimitar o termo "política" no campo da ciência política apresenta uma divisão em três partes complementares entre si: "polity”, "politics" e "policy”. A expressão "polity" é para denominar as instituições políticas, "politics" para verificar os processos políticos e, por fim, "policy” para estabelecer os conteúdos da política. Mais especificamente podese definir como:

- [...] a dimensão institucional 'polity' se refere à ordem do sistema político, delineada pelo sistema jurídico, e à estrutura institucional do sistema políticoadministrativo;

- [...] no quadro da dimensão processual 'politics' tem-se em vista o processo político, freqüentemente de caráter conflituoso, no que diz respeito à imposição de objetivos, aos conteúdos e às decisões de distribuição;

- [...] a dimensão material 'policy' refere-se aos conteúdos concretos, isto é, à configuração dos programas políticos, aos problemas técnicos e ao conteúdo material das decisões políticas (FREY, 2000, p.216-217).

Como se pode observar, o termo "política" deve ser compreendido de forma abrangente e subdividido entre as instituições (polities), agentes (politics) e os programas (policies). Embora eles se constituam separadamente com uma lógica própria, ocorre uma articulação entre si. Segundo Frey (2000), o conjunto das relações 
entre o tripé "polity", "politics" e "policy", constituem os elementos da "policy analysis". Tais questões em síntese referem-se à busca pelo entendimento sobre o que os governos fazem, porque o fazem e principalmente que diferença isto faz no seio de uma sociedade civil organizada (DYE, 1976). Na esteira destas definições, Ham e Hill (1993) enfatizam que um aumento do conhecimento sobre o processo de elaboração das ações de governo pode proporcionar, a melhoria da qualidade das políticas públicas desenvolvidas, já que permite a extensão e a melhoria das informações disponibilizadas aos "policy makers" (decisórios políticos).

Também se deve levar em consideração que as relações entre as três dimensões (polity, politics e policy) apresentam suas disputas de poder no campo político. Mezzadri (2011) lembra que as disputas e interações entre os agentes e as instituições no interior deste campo sempre deixarão suas marcas nos programas e projetos desenvolvidos pelos governantes. Para compreender todo o campo que envolve a política pública, torna-se necessário avançar a discussão sobre a "policy analysis". Neste ponto, conforme aponta Frey (2000), destacam-se duas dimensões: "policy arena" e "policy cycle". A primeira insere em seu contexto os conteúdos, os agentes e as instituições, referindo-se aos processos de conflito e consenso dentro das diversas áreas da política. As áreas da política podem ser apontadas de acordo com o seu caráter e caracterizada quanto à forma, aos efeitos de implementação aplicados aos conteúdos das políticas e ao modo da resolução de conflitos políticos. Neste sentido, Souza (2006) destaca que a "policy arena" deve ser compreendida como cada tipo de política pública vai encontrar diferentes formas de apoio e de rejeição e que as disputas em torno de sua decisão passam por arenas diferenciadas. 
Já a "policy cycle" determina suas fases, desde o processo de definição das demandas sociais até a avaliação das mesmas (FREY, 2000). O ciclo completo da política pública é constituído dos seguintes estágios: a) percepção e definição do problema; b) elaboração de programas e decisão (planejamento); c) implementação de políticas; d) avaliação de políticas e correções das ações (SOUZA, 2006). A compreensão de cada uma das fases da "policy cycle" é de fundamental importância para que as políticas públicas (policies) possam ser construídas e implementadas com o objetivo de responder às demandas sociais e melhorar as condições da sociedade. Entretanto, conforme aponta Mezzadri (2011), essa interação dos agentes e instituições na "policy cycle" depende da estratégia utilizada no processo da construção das políticas públicas. Deubel (2006) argumenta que o sentido de uma implementação depende da dinâmica das interações e disputas no interior da gestão pública, da participação da sociedade e das outras instituições envolvidas na área. O autor ainda lembra que é de primordial importância a interpretação e a reinterpretação dos fatos ocorridos na "policy cycle" para melhorar as ações realizadas. Nesse sentido, esta pesquisa ampara-se no referencial teórico de políticas públicas acima descrito.

\section{Metodologia}

Como instrumento para a operacionalização desta base conceitual, utilizou-se da modalidade de análise documental, tendo como modelo os procedimentos preconizados por Bardin (2006). Para complementar estes dois primeiros passos, foram utilizadas, também, entrevistas narrativas (JOVCHELOVITCH; BAUER, 2002).

Para selecionar as fontes analisadas inicialmente, fez-se um mapeamento das instituições ("polities”) envolvidas no processo de construção de legados, a seleção dos 
documentos pertinentes ao tema delimitado e dos agentes que pudessem responder a questões fundamentais para o desenvolvimento da análise. As fontes escolhidas foram: a) DC do Rio de Janeiro a Sede dos JO/PO de 2016 e os CLs Olímpicos Rio 2016; b) web pages oficiais do governo brasileiro e documentos oficiais de prestação de contas; c) entrevistas com dois agentes da Autoridade Pública Olímpica (APO), os quais foram denominados agente 1 e agente 2; d) entrevista com um agente da SNELIS, denominado agente 3. Cada entrevista, com duração média de 60 minutos, foi gravada em formato digital e transcrita posteriormente. E, por fim, e) outros documentos sobre esporte de lazer, megaeventos esportivos, políticas públicas e legados, que serviram como fontes secundárias da pesquisa, ou seja, contribuíram para um entendimento global do tema estudado.

\section{Resultados e discussões}

\section{A) O esporte de lazer no Dossiê de Candidatura e Cadernos de Legados Rio}

\section{6}

Reis e Sousa-Mast (2012) indicam que, até o ano 2000, o Comitê Olímpico Internacional (COI) não havia dado ênfase ao planejamento dos legados em suas avaliações das cidades candidatas, nem de uma forma geral e muito menos a legados intangíveis e de difícil mensuração, como é o caso do legado de participação esportiva (DONNELLY, 2008). A partir da criação do Estudo de Impacto dos Jogos Olímpicos (Olympic Games Impacts - OGI), pelo COI, os impactos começaram a ser tratados de uma maneira mais cuidadosa e medidos em longo prazo. Segundo Villano et al. (2008), os possíveis legados gerados pela organização de um megaevento esportivo podem ser 
divididos em cinco categorias, a saber: a) legados do evento em si; b) legados da candidatura do evento; c) legados da imagem do Brasil; d) legados de governança; e e) legados de conhecimento.

Conforme essa categorização, os legados referentes ao esporte de lazer, fazem parte do primeiro grupo - "do evento em si" -, abrangendo construções esportivas e de infraestrutura da cidade, compra de equipamentos esportivos, de segurança, telecomunicações, informática, etc., ocupações de empregos temporários e/ou permanentes, abertura de novas possibilidades e oportunidades de trabalho especializado, promoção e realização de outros eventos, bem como o aumento da procura de práticas de atividades físicas por parte de população. Sobre a questão dos legados, o trecho do depoimento do agente 1 da APO diz que, com referência à proposta de aumento da atividade física para a população, é importante que seja prevista sua sustentabilidade, pois é fácil conseguir investimentos em um momento em que o esporte está em evidência e, passado isso, não ter como manter o que se conseguiu. Para ele, "seria como incentivar as pessoas, principalmente as crianças e jovens, à prática esportiva e depois, por falta de financiamento, retirar essa possibilidade", e exemplifica, "[...] hoje temos $\mathrm{X}$ de investimento, ano que vem XX e no outro ano, $\mathrm{XXX}$, e depois dos jogos, voltamos ao $\mathrm{X}$ inicial - isso não é legado, é processo. E um processo que recuou. Ao propor essa ampliação, é importante ver como se dará sua manutenção e permanência após os jogos.” (AGENTE 1, 2013, s.p.).

Os benefícios deixados por um megaevento devem ser estendidos a toda a população. No entanto, para que isso ocorra, os "policy makers" precisam buscar uma forma de administrar os legados de modo que não atendam apenas às necessidades esportivas específicas e/ou aos interesses políticos e/ou econômicos (SOUZA, et. al 
2013). Neste momento, uma questão fundamental precisa ser mencionada, afinal, para que todos os benefícios supracitados se concretizem no ciclo da política pública (policy cicle), são necessárias "policies" bem elaboradas e, para que isso ocorra, é necessária uma ação forte entre as "polities" (instituições) e "politics" (agentes), não devendo confundir as "policies” com somente a dimensão do financiamento monetário.

A fim de detalhar os documentos oficiais que tratam desses benefícios deixados por megaeventos esportivos, bem como as menções que fazem a tais benfeitorias, revisaram-se alguns documentos como o DC do Rio de Janeiro - a sede dos JO/PO de 2016 - e os CLs. As informações contidas em tais documentos contribuem para a compreensão de uma parte da "policy cycle" (FREY, 2000; SOUZA, 2006), apresentando elementos dos dois primeiros estágios (percepção e definição do problema; elaboração de programas e decisão) dos programas, projetos ou ações a serem realizados para o campo esportivo no país.

Sobre o DC, sabe-se que o COI exige a entrega de 100 cópias do documento de todas as cidades candidatas, servindo de base para a análise técnica de cada projeto. $\mathrm{O}$ DC do Rio tem 600 páginas divididas em três volumes, contendo informações sobre 17 temas, como, por exemplo, transporte, acomodações e meio ambiente. Nele, é possível encontrar textos, manuais técnicos, mapas, tabelas e projetos arquitetônicos das instalações previstas. Nesse documento, observamos que o plano de legado apresenta quatro prioridades-chave, a saber: 1) Transformação da cidade; 2) Inserção social: habitação, treinamento e emprego; 3) Juventude e educação; 4) Esportes (COMITÊ RIO 2016, 2009).

Referente à "Transformação da cidade", aponta-se: a importante renovação de infraestrutura na Barra da Tijuca, principalmente nas instalações esportivas, de lazer e 
de transporte, e o Parque Radical de Deodoro - zona com o maior percentual de jovens da cidade, com uma ampla variedade de instalações esportivas e de lazer. Sobre "Inserção social: habitação, treinamento e emprego", temos: aquisição de bens para os JO/PO - na medida do possível, o Comitê Organizador (CO) Rio 2016 se comprometerá em adquirir serviços e equipamentos para os $\mathrm{JO} / \mathrm{PO}$ nas comunidades locais e apoiará o licenciamento de produtos ambiental e socialmente responsáveis, como foi feito durante os Jogos Pan-americanos Rio 2007.

Nesse momento, pelo tema abordado no artigo, interessa ver com mais detalhe os dois últimos pontos: Juventude e Educação; Esportes. Sobre a prioridade-chave "Juventude e Educação", comenta-se que o compromisso do GF de proporcionar acesso à associação entre educação e esporte a todos os brasileiros será favorecido pelo CO Rio 2016. Estão entre as iniciativas: a) Ampliação do Programa Segundo Tempo (PST) - de 1 milhão de crianças (2009), o programa passaria a atender 3 milhões de crianças até 2016; b) Investimento de mais de US\$ 400 milhões no Mais Educação entre 2009 e 2016. Os métodos de ensino seriam melhorados, reforçando o objetivo global, que é popularizar as aulas de Educação Física e esporte em todos os estabelecimento escolares. Da mesma forma, os Jogos Escolares e Universitários seriam ampliados - de 2,5 milhões, o evento passaria a atender 5 milhões de estudantes (COMITÊ RIO 2016, 2009).

Já na prioridade-chave "Esporte", afirma-se que, além do legado físico das instalações esportivas e dos voluntários treinados para os $\mathrm{JO} / \mathrm{PO}$, o plano de legados também envolve iniciativas que visam ao desenvolvimento do esporte no Brasil, na América do Sul e no resto do mundo. Entre elas, citam-se: a) Bolsas para atletas - até 11.000 jovens brasileiros, que não recebiam apoio de patrocinadores privados, 
receberiam ofertas de bolsas até 2018; b) Bolsas do Centro Olímpico de Treinamento a parceria entre a Solidariedade Olímpica e o Centro Olímpico de Treinamento ofereceria bolsas a atletas e treinadores de todas as partes do mundo. As bolsas prorrogariam os programas internacionais que já estavam em vigor no Brasil e estariam alinhadas com os programas do COI; c) Aumento de investimentos federais no esporte um aumento de mais de US\$ 210 milhões ajudaria a preparar as equipes Olímpicas e Paralímpicas; d) Legado de instalações de treinamento - seria deixado um legado de 14 instalações fora do Rio e 29 dentro da cidade. Estas últimas estariam localizadas dentro das comunidades e próximas a escolas públicas; e) Formação de técnicos a nível nacional - a partir de discussões com as Confederações Brasileiras de esportes menos desenvolvidos no Brasil, foram formulados projetos de treinamento e formação no Rio e em toda a América do Sul. Os cursos melhorariam as competências técnicas e deixariam um legado de novos técnicos sul-americanos (COMITÊ RIO 2016, 2009).

Comenta-se que, além disso, o programa Rio Olímpico consolidaria diversas ações existentes que promoveriam o aumento dos investimentos nos novos programas e na infraestrutura vinculada ao esporte. Tais financiamentos ainda permitiriam a promoção do esporte e o acesso das comunidades às instalações dos Jogos. Os JO/PO de 2016 seriam beneficiados por um aumento nos investimentos do setor privado através de programas de incentivo fiscal já em vigor. O financiamento deveria passar de US\$ 80 milhões a, pelo menos, US\$ 200 milhões até 2016, e apoiaria diversas instalações esportivas e a criação de programas ligados ao esporte (COMITÊ RIO 2016, 2009).

Com referência à avaliação do sucesso, expõe-se que instrumentos de controle, como, por exemplo, o OGI do COI, serão utilizados para que se elaborem relatórios para o COI, Comitê Paralímpico Internacional (IPC) e organizações locais. Tais 
instrumentos também auxiliariam no processo de tomada de decisões do CO Rio 2016 e da APO. Segundo o Comitê Rio 2016 (2009), os JO/PO Rio 2016 seriam liderados por um Conselho Olímpico, estruturado para promover integração entre CO Rio 2016 e os três níveis do governo, juntamente com Comitê Olímpico Brasileiro (COB) e Comitê Paralímpico Brasileiro (CPB). A estrutura Olímpica integrada para os JO/PO de 2016 previa, ainda, a criação da APO, uma agência com a finalidade específica de coordenar e garantir as entregas relativas aos $\mathrm{JO} / \mathrm{PO}$.

Os CLs Rio 2016 são fruto da articulação entre as três esferas do governo, durante o processo da candidatura brasileira, que alinhou o projeto olímpico ao planejamento de longo prazo da cidade, através do Plano Diretor, e do país, por meio do Plano de Aceleração do Crescimento (PAC). O texto divide-se em: a) CL Urbano e Ambiental, que mostra todo o plano de revitalização e regeneração de diversas zonas do Rio de Janeiro, assim como a implantação do sistema de transporte de massa Bus Rapid Transit (BRT) e a expansão do metrô e de trens metropolitanos; b) CL Social, que apresenta o plano de disseminação de programas socioesportivos do ME e de redução do déficit de infraestrutura esportiva na rede pública de ensino brasileira; c) CL Brasil, que contém diversos dados sobre o país e sobre a cidade sede que pudessem dar ao COI uma visão global da nação, mostrando que está preparada para sediar grandes eventos esportivos.

Dentre os três, destaca-se o CL Social. No entanto, vale mencionar uma parte do CL Brasil, que aponta o Legado Esportivo como a principal herança dos jogos ao país. O mesmo procurará garantir que a prática esportiva e a atividade física disseminem-se amplamente no cotidiano do país. Já no Legado Social, é comentado que são previstas oportunidades inéditas para as camadas ditas vulneráveis e que compõem uma grande 
parte da população da cidade sede brasileira. Para o ME, o principal foco é dado à juventude, que terá a oportunidade de ter qualificação profissional e formação cidadã, através dos valores universais do olimpismo (BRASIL, 2009a).

No CL Social (BRASIL, 2009b), o Legado deverá transcender a propagação dos valores olímpicos (excelência, amizade, solidariedade, respeito e fair play) e permitirá o acesso ao esporte, ao lazer, à cultura e à qualificação profissional, através de políticas "policies" adotadas pelo governo (em suas três esferas), possibilitando que milhares de jovens em situação de vulnerabilidade exerçam seu direito de cidadão e tenham uma porta aberta para o futuro. Explica-se ainda que, em parceria com toda a sociedade civil, os projetos serão potencializados para expandir sua abrangência, incrementar seu público e diversificar suas atividades. Tendo-se em vista a candidatura a outros eventos, principalmente os $\mathrm{JO} / \mathrm{PO}$ de 2016 , foi introduzido pelo GF o debate entre as partes envolvidas (policy arena). Para o órgão, a ideia principal, em harmonia com a opinião do COI, é a de que os megaeventos esportivos possam estimular o desenvolvimento social, reunindo múltiplas ações que visem à melhoria das condições de vida das comunidades pobres das cidades-sede.

Dessa forma, o legado surgiu como oportunidade para iniciar uma discussão na "policy arena" sobre quais seriam os investimentos e onde estes seriam aplicados e/ou ampliados, para beneficiar as comunidades menos favorecidas. Esse conceito vem evoluindo e se materializando nas propostas de legado para 2016, detalhadas, particularmente, no CL Social. Nesse ponto, é divulgado que algumas comunidades do RJ passaram a se beneficiar dos resultados de programas governamentais baseados nesse conceito. Entre as principais ações de integração social citadas, encontra-se uma política pública do GF já em funcionamento: o PELC (BRASIL, 2009b). 
No documento, é ressaltado que um dos maiores legados que um evento como os JO/PO pode deixar é o aumento do interesse de crianças e jovens pela prática esportiva, que pode ser melhorado quando associado a oportunidades de formação educacional, profissional e cultural. No caderno, o GF afirmou que iria ampliar as metas de programas nacionais que aliavam o esporte e o lazer à educação. Verificou-se que, além da promessa de provocar a expansão dos núcleos do PELC, há o registro de que a consolidação da Rede CEDES (Centro de Desenvolvimento do Esporte Recreativo e do Lazer) também seria estimulada pelos JO/PO de 2016 (BRASIL, 2009b).

Neste mesmo caderno, constata-se que a prefeitura do Rio de Janeiro iria incrementar o projeto de Vilas Olímpicas - equipamentos esportivos que contam com pista de atletismo, piscina, quadras esportivas e campo de futebol, oferecendo atividades esportivas, recreativas e culturais. Nesses centros esportivos são descobertos talentos do caratê, taekwondo e outros esportes. Segundo o documento, os JO/PO deixarão como legado material uma maior estrutura de equipamentos esportivos, contratação de milhares de monitores, reposição de materiais esportivos em todo o país. Com a mesma importância, também deixarão a iniciação esportiva e a disseminação da prática do esporte associada a valores de cidadania e educação (BRASIL, 2009b).

\section{B) Controle, mensuração e entrega dos legados}

Aprofundando um pouco mais na materialização destes legados, entra-se no terceiro estágio da "policy cycle", através de algumas instituições (polities) que fazem um acompanhamento da implementação das "policies" para que os objetivos se concretizem. Vale lembrar que, elaborar políticas e acompanhar sua implementação, 
não é a função principal destas instituições, mas, de uma forma ou de outra, elas acabam se envolvendo nessas etapas.

Entre estas "polities", destaca-se a APO, uma autarquia em regime especial, criada em 2011, através de um contrato de consórcio público interfederativo (GF, Estado e Município do Rio de Janeiro), com o objetivo de coordenar a participação destas "polities" na preparação e realização dos JO/PO 2016, principalmente para garantir o cumprimento das obrigações assumidas perante o COI. Sua sede é na cidade do Rio de Janeiro, mas pode atuar em outros municípios e estados para tratar assuntos referentes aos Jogos. Ressalta-se que, entre outras funções, à entidade caberia, toda a articulação da "policy cycle": a) Adquirir terrenos necessários para os JO/PO através de desapropriação; b) Projetar, licitar e entregar os principais elementos de infraestrutura dos $\mathrm{JO} / \mathrm{PO}$, trabalhando em colaboração com todas as esferas da "policy arena", ou seja, as autoridades Federais, Estaduais e Municipais, bem como com o CO Rio 2016 em cada projeto; c) Fornecer instrumentos formais para a coordenação entre os Governos e o CO Rio 2016 em relação aos JO/PO; d) Garantir o alinhamento das iniciativas do evento e do legado com as estratégias governamentais de longo prazo para eventos e legado; e) Viabilizar o apoio do setor público para os JO/PO, coordenando as ações dos três níveis de governo (COMITÊ RIO 2016, 2009).

Na ocasião da entrevista com o agente 1, este afirmou que "na APO ninguém dá um passo sem consultar o Dossiê e os Cadernos de Legados. É como se tivéssemos uma diretriz primeira e única, que são os compromissos assumidos no Dossiê, nos Cadernos e no Ato Olímpico.” (AGENTE 1, 2013, s.p). Nessa mesma ocasião, o agente 2 (2013, s.p.) resumiu que o dever da entidade é acolher as demandas que chegam referentes à organização e realização dos JO/PO 2016, entrar como facilitadora/articuladora dos 
processos e garantir que os três entes que constituem esse consórcio cumpram o que prometeram entregar nos $\mathrm{JO} / \mathrm{PO}$.

Além da APO, há outras instituições e mecanismos presentes na "policy arena" e que também são responsáveis por fazer o controle dos legados do evento. Na página web Rio 2016 do $\mathrm{CO}$ dos $\mathrm{JO} / \mathrm{PO}$ - empresa privada sem fins lucrativos, responsável pelo planejamento, entrega e legado dos jogos e que trabalha em conjunto com os níveis municipal, estadual e federal do governo, com patrocinadores, apoiadores e com a comunidade esportiva -, é possível encontrar a notícia (08/02/13) de que tal Comitê e o Laboratório de Sistemas Avançados de Gestão da Produção (SAGE) da Coordenação de Programas de Pós-Graduação em Engenharia (COPPE/UFRJ) assinaram o contrato para a realização do OGI dos JO/PO de 2016. O estudo em questão consiste em analisar todo o ciclo da política pública (policy cycle), pois suas ações consistem em um conjunto de relatórios que consolidam indicadores utilizados para medir os efeitos e impactos ambientais, socioculturais e econômicos dos JO/PO em áreas como educação, saúde, segurança, esporte, lazer e infraestrutura. O Conselho Científico que atuará no detalhamento do OGI é formado por oito consultores em acessibilidade, economia, biologia, áreas social e esportiva. Serão produzidos quatro relatórios referentes ao período de 12 anos - o primeiro tinha a data de divulgação marcada para setembro de 2013, abrangendo o período de 2007-2012 (ainda não divulgado); o de 2014 trará resultados específicos do evento, com todos os indicativos, atualizações e análises qualitativas; em 2017, o relatório trará indicadores do período dos JO/PO; e, em 2019, se apresentará a análise do período completo (RIO 2016, 2013).

O agente 1 lembrou que "todos estes entes (Governos, CO Rio 2016, APO...) estão envolvidos com o Legado, cada um dentro de uma perspectiva” e observou que 
“este é um tema estratégico que está no planejamento de todos, mas, a princípio, a coordenação do Legado Estratégico está com o ME.” (AGENTE 1, 2013, s.p.).

Até aqui se pode observar o tratamento dispensado ao esporte de lazer no DC e nos CLs, por meio de propostas e previsões para a área, bem como mecanismos que possam garantir o cumprimento de tais propostas.

\section{C) Planejamento, ações e financiamento para o esporte de lazer no âmbito do}

\section{Governo Federal}

Nesta parte do estudo, faz-se necessária uma breve exposição de como se divide e funciona o órgão responsável pelas principais ações levadas a cabo na área do esporte de lazer dentro do GF, ou seja, a base da "policy arena" e os "policy makers" do esporte brasileiro. As informações foram retiradas do site do ME, do Catálogo do PELC (BRASIL, 2008), da obra de SOUSA et al. (2010) e da entrevista com o agente 3 (2013, s.p.), da SNELIS.

Da fusão da antiga Secretaria Nacional de Desenvolvimento do Esporte e do Lazer (SNDEL) com a Secretaria Nacional de Esporte Educacional (SNEED), em 2011, surgiu a SNELIS. Dois departamentos fazem parte da nova secretaria: 1) Departamento de Gestão de Programas de Esporte, Educação, Lazer e Inclusão Social; 2) Departamento de Desenvolvimento e Acompanhamento de Políticas e Programas Intersetoriais de Esporte, Lazer e Inclusão Social. Há diversos programas ofertados por essa Secretaria. No entanto, se descreverá de uma forma breve apenas o PELC, já que é o único programa sobre o esporte de lazer, mencionado no CL Social.

Com a finalidade de desenvolver uma proposta de política pública, que atenda às necessidades de esporte de lazer da população, o PELC oferece atividades de oficinas 
esportivas, ginástica, teatro e música para pessoas de todas as idades, através de núcleos implantados nas diversas comunidades. Através do PELC, o ME ainda financia eventos em parceria com prefeituras, estados, organizações não governamentais (ONGs), instituições de ensino superior e Organizações da Sociedade Civil de Interesse Público (OSCIPs). Atualmente, o PELC está representado, prioritariamente, por três ações: A) Núcleos Todas as Idades, que envolvem todos os segmentos (criança, adolescente, adulto, idoso, pessoas com deficiência e outras necessidades educacionais especiais); B) Núcleos do Programa PELC/Vida Saudável, específicos para o atendimento da faixa etária a partir dos 45 anos, com vistas à melhoria da qualidade de vida dessa população, sem abrir mão do atendimento a pessoas com deficiência; C) Núcleos para os Povos e Comunidades Tradicionais.

Segundo informações fornecidas pelo agente 3 (2013, s.p.), a parceria PELC/PRONASCI (Programa Nacional de Segurança Pública com Cidadania), que acontecia com o Ministério da Justiça, já não existe desde 2012, apesar de ainda constar no site do ME. O agente também revelou que, ainda em 2013, sairia novo edital com algumas novidades. Entre elas, o desmembramento do núcleo Vida Saudável do PELC, tornando-se um programa específico da Secretaria.

Outra informação relatada pelo entrevistado da SNELIS é a de que a Rede CEDES, também mencionada no CL Social e que era um eixo do PELC, está desde 2011 - após a fusão da SNEED e da SNDEL - sob a responsabilidade da Secretaria Executiva do ME, que conta com o auxílio da SNELIS. Segundo aponta Starepravo (2011), a Rede reúne instituições de ensino superior (públicas e privadas), que compõem diversos núcleos. Esses grupos são estimulados a produzir e difundir conhecimentos fundamentados nas Ciências Humanas e Sociais, voltados para o 
aperfeiçoamento e a qualificação de todas as etapas da "policy cycle". O objetivo articular o conhecimento produzido, para utilizá-lo na construção de uma política nacional de esporte e lazer.

Além desses programas, pode-se citar, como uma questão importante para o financiamento do esporte de lazer do país, o Plano Plurianual (PPA) do GF. O PPA é um instrumento de planejamento da ação de governo, previsto pelo Artigo 165 da CF, que define diretrizes, objetivos e metas com o propósito de viabilizar a implementação e a gestão das políticas públicas, orientar a definição de prioridades e auxiliar na promoção do desenvolvimento sustentável do país (STAREPRAVO, 2011).

O que está em vigor atualmente é o PPA Mais Brasil (2012-2015). Verifica-se a importância do Plano, através do aumento de recursos destinados ao PPA de 20042007 para o de 2012-2015, que passou de R\$ 2,4 trilhões para R\$ 5,5 trilhões. Constata-se que, no PPA 2008-2011, o esporte não é tratado com destaque, apenas sendo apontados em uma tabela os dispêndios previstos para o setor Desporto e Lazer. Por outro lado, o PPA atual dá grande ênfase ao tema (BRASIL, 2011).

Dentre as principais metas do Programa Temático 2035 - Esporte e Grandes Eventos Esportivos -, destacam-se: 1) criação de projetos de esporte e atividade física, que contribuam para a promoção da saúde e da qualidade de vida da população; 2) ampliação do acesso de crianças, adolescentes e jovens escolares ao esporte, com ênfase em áreas de vulnerabilidade social; 3) apoio aos atletas de modalidades olímpicas e paralímpicas, que preencham os requisitos e se candidatem à Bolsa-Atleta; 4) coordenação do Comitê Gestor para a Copa 2014; e 5) implantação e modernização da infraestrutura esportiva necessária à realização dos $\mathrm{JO} / \mathrm{PO}$ 2016. Ainda no documento, existe a informação de que a política de esporte do PPA 2012-2015 
envolve alguns desafios, como a ampliação de equipamentos públicos; a construção de recursos institucionais; o papel do esporte na inclusão social; o estímulo a práticas e estilos de vida saudáveis; e o fomento ao potencial econômico do esporte, em especial do futebol. Cita-se como meta a implementação de 800 Praças do Esporte e da Cultura, denominadas, agora, Centro de Artes e Esportes Unificados (CEUs), levando serviços e equipamentos às áreas pobres das grandes cidades brasileiras. Já sobre os grandes eventos, comenta-se que os esforços estarão voltados para a organização das ações para a realização da Copa 2014 e para os JO/PO 2016. No documento, são destacados os desafios associados aos possíveis legados (esportivo, social, urbano e ambiental), deixados pelos grandes eventos (BRASIL, 2011).

No item Função Desporto e Lazer (FDL) do documento "Prestação de Contas da Presidenta da República/2012", podemos encontrar diversos dados sobre o financiamento do GF para a área (BRASIL, 2013). Neste, encontra-se um quadro (BRASIL, 2013, p. 361) que apresenta os valores liquidados das despesas do ME para a FDL, no período de 2008 a 2012. Tais valores referem-se aos serviços executados e são a somatória dos valores liquidados no ano relativo ao orçamento do próprio exercício e os valores liquidados no ano relativos a restos a pagar não processados inscritos em exercícios anteriores. A FDL tem como subfunções típicas: Desporto de Rendimento, Desporto Comunitário e Lazer. Observa-se que a subdivisão dos segmentos esportivos não é feita da mesma maneira que aparece na legislação brasileira. Nesse formato, o PELC se enquadra na subfunção típica Desporto Comunitário, juntamente com a vertente de esporte educacional. A partir dos dados retirados desse quadro, apresenta-se o seguinte gráfico: 


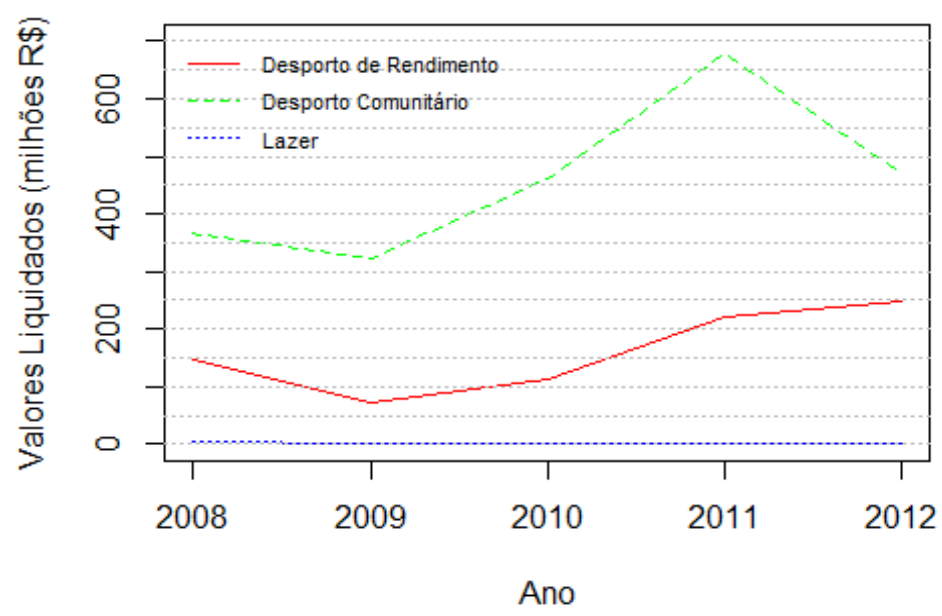

Quanto à execução na subfunção Desporto Comunitário, onde se encontram os gastos direcionados à inclusão social pelo esporte, funcionamento de núcleos de esporte educacional e de lazer, bem como a implantação e modernização de instalações esportivas, verifica-se que há uma evolução. Ainda que o Gráfico 1 nos mostre um alto investimento nessa subfunção, sua mensuração se torna difícil quando se pensa onde os benefícios deveriam chegar, ou seja, até a população. No documento, explica-se que os valores apurados demonstram uma evolução de investimentos no desenvolvimento de políticas públicas na área esportiva, bem como na preparação da Copa do Mundo 2014 e JO/PO 2016. Comenta-se, ainda, que a execução orçamentária indica que a Subfunção Desporto de Rendimento apresenta tendência de elevação dos gastos a partir de 2011, mantendo a tendência em 2012, fato que resulta do acréscimo de recursos destinados ao apoio às equipes e aos atletas, financiados pelas ações "Preparação de Atletas", “Concessão de Bolsa a atletas" e à preparação para a realização dos dois megaeventos (BRASIL, 2013). 
Outra fonte importante para a pesquisa foi o Portal da Transparência do GF, que disponibiliza a transferência de recursos por programa e por ano. A partir da pesquisa sobre os dados do PELC nesse Portal, organizou-se um gráfico que mostra os valores destinados ao programa de 2008 a 2012. Da mesma forma, estão sendo apresentados os valores destinados à subcategoria "Implantação e Modernização de Infraestrutura para ERL" do PELC:

Gráfico 2 - recurso total destinado ao pelc e valor aplicado (do total) em implantação e modernização de infraestrutura para erl de 2008 A 2012.

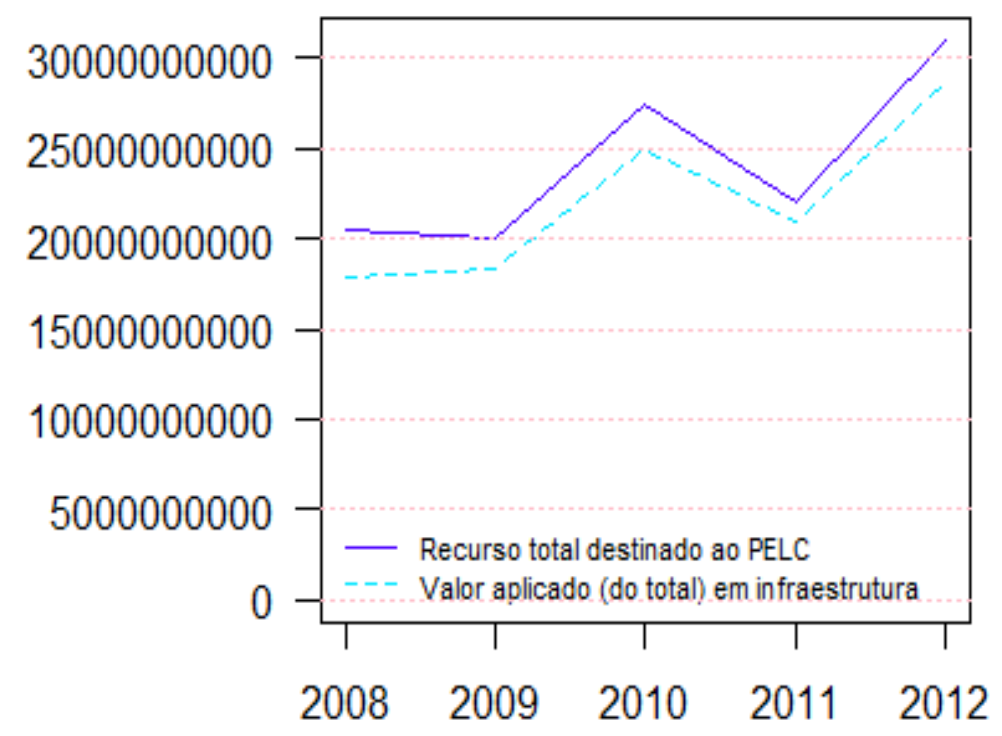

Ano

Percebe-se que os valores destinados ao PELC, de 2008 a 2012, oscilam de uma forma não linear, apresentando saltos de 2009 para 2010 e de 2011 para 2012. Pareceu importante expor a subcategoria "Implantação e Modernização de Infraestrutura para ERL" no gráfico, pois representa, dos anos de 2009 a 2012, mais de $90 \%$ do total do recurso para o programa. Esse dado pode ter relação com a informação do Gráfico 1, onde se questionou a chegada dos recursos à população, pois, mais de $90 \%$ do recurso 
destinado ao PELC aplica-se à implantação e modernização de infraestrutura e não à implantação de núcleos PELC - o que, a priori, é a proposta do programa.

Outra ferramenta utilizada foi o DadosGov, que tem link direto com o site do GF e disponibiliza informações sobre ações governamentais, coletadas no Balanço de Governo de 2003-2010. Os dados do Gráfico 3, que mostra o número total de núcleos do PELC, de 2008 a 2012, foram retirados deste site (2003-2010) e dos documentos “Prestação de Contas da Presidenta da República" - exercícios 2011 e 2012 (BRASIL, 2012, p. 532; BRASIL, 2013, p. 358).

Gráfico 3 - número total de núcleos do pelc de 2008 a 2012.

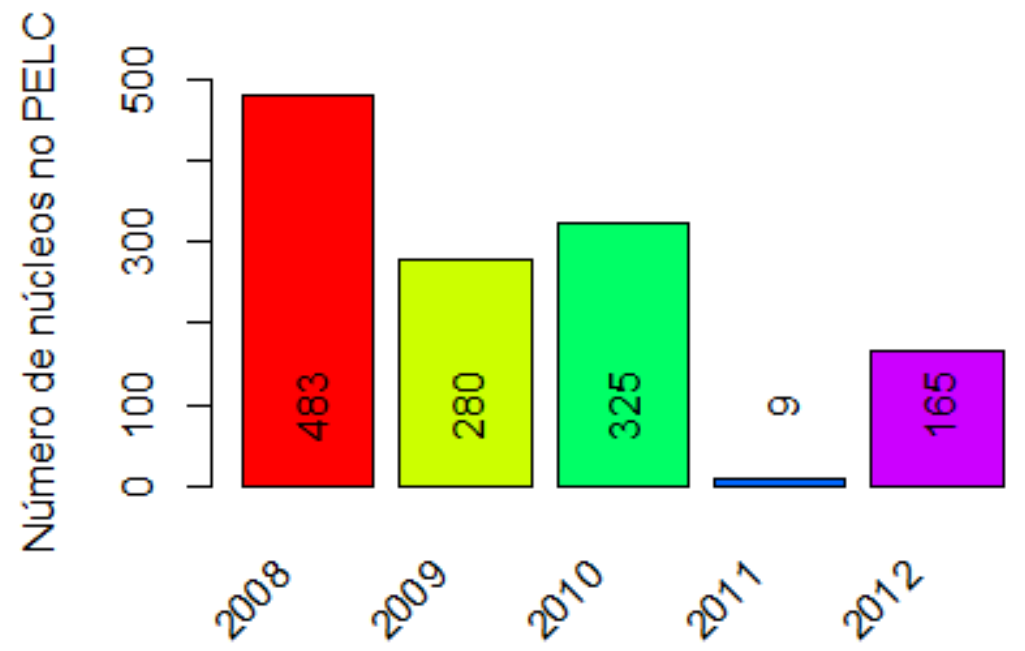

Confrontando os dados desse gráfico com os do Gráfico 1, verifica-se a aproximação entre as informações, já que, a partir de 2011, houve uma grande queda nos valores liquidados para o Desporto Comunitário, período em que o número de núcleos PELC diminuiu significativamente. Na comparação destes dados com o Gráfico 2, constata-se a concordância entre ambos, pois, se os recursos estão sendo aplicados quase que completamente na infraestrutura, destinando-se pouco menos de $10 \%$ do total 
a todas as demais subcategorias que compõem o PELC, o resultado lógico é a redução do número de núcleos que atendam diretamente à população. Sobre a queda expressiva no número de núcleos em 2011, verifica-se que no site do ME existe a informação de que não houve edital para o orçamento de 2011, pela necessidade de conclusão dos convênios aprovados em 2010.

Este esfriamento pode advir das disputas existentes entre os diversos agentes na "policy arena". Tais pontos se repercutem na fala do agente 3, que argumenta que, após a fusão das duas secretarias em 2011, "houve uma fase de reestruturação da nova secretaria em que tudo deu uma parada." (AGENTE 3, 2013, s.p.). Os gráficos apresentados também corroboram com este argumento. Afinal, os dados mostram o que vem acontecendo com o financiamento para as áreas do esporte, desde que o Rio de Janeiro foi eleito como sede dos Jogos Olímpicos. Verifica-se que foi destinado um orçamento expressivo ao esporte de lazer, no entanto, os altos valores despendidos com

o PELC estão sendo destinados, quase que completamente, à implantação e modernização de infraestruturas esportivas, que podem, ou não, ser utilizadas para o esporte de lazer.

\section{D) As relações entre as propostas de esporte de lazer inseridas no DC e nos}

\section{CLs Rio 2016 com a "policy cycle"}

Observou-se que um ponto em evidência entre as formas de legados presentes nos dois documentos diz respeito à infraestrutura, instalações e equipamentos. Também se mostram intenções referentes à universalização do esporte e à inclusão por meio das vertentes educacional e participação. No entanto, nota-se que a prioridade dos "policy makers" é o desenvolvimento do esporte de rendimento materializado nas seguintes 
"policies": bolsas para atletas; Centro Olímpico de Treinamento; aumento de investimentos federais no esporte, na preparação das equipes Olímpicas e Paralímpicas e formação de técnicos.

Com a vinda dos megaeventos para o Brasil, mudanças no cenário esportivo começaram a acontecer. $\mathrm{O}$ esporte como um todo recebeu atenção especial, leis foram formuladas e/ou reformuladas e criaram-se novos órgãos, programas e projetos para o esporte. Com a criação da SNELIS, extinguiu-se uma secretaria específica do esporte de lazer (SNDEL), que teve seus assuntos unidos à secretaria responsável pelo esporte educacional. Teve-se, aqui, um exemplo das disputas presentes na arena política, que acabaram interferindo significativamente na implementação de políticas públicas de esporte no país. Sobre a extinção da SNDEL e essa disputa existente, o agente 2 (2013, s.p.) comenta que se pode imaginar que "está tudo contemplado porque está tudo junto em outra secretaria, mas se enfraqueceu um trabalho que estava muito interessante".

Referente ao planejamento, ações e financiamento do GF, existem menções consideráveis para o esporte de lazer, como a previsão de construção de 800 CEUs, implantação do PELC em mais da metade dos municípios brasileiros, bem como um investimento em construção e reformas de quadras de escolas, junto à aquisição de equipamentos esportivos. Mesmo assim, percebe-se que essa manifestação do esporte não é priorizada no momento. As disputas travadas no interior da "policy arena" que, por sua vez, também sofrem influência dos "policy makers", acabam determinando o conteúdo das "policies". O resultado dessas disputas pode ser verificado na criação de novos programas para o esporte neste período pré-JO/PO. Envolvendo o esporte de lazer, têm-se apenas os CEUs. Por outro lado, envolvendo o esporte de rendimento, 
foram criados e/ou alterados: Centro de Iniciação Esportiva; Plano Brasil Medalhas; Rede Nacional de Treinamento; Atleta Pódio e Bolsa Técnico.

Além disso, percebe-se que as relações de poder dentro da arena política acabam por preterir o esporte de lazer. Tais elementos ficam evidentes nos comentários dos agentes entrevistados da APO, quando estes falam sobre o acolhimento de demandas "as que chegaram primeiro foram as do alto rendimento, do estado, do município e das universidades" (AGENTE 2, 2013, s.p.) - e sobre o trabalho que está em andamento “infraestrutura e outras aquisições para a realização dos jogos, por motivo de cumprimento de prazos", lembrando que as ampliações para o esporte de lazer podem vir a qualquer momento (AGENTE 1, 2013, s.p.). A fala do agente 3 (2013) confirma esta ideia de desequilíbrio, ao dizer que, para o PELC e para a SNELIS, praticamente não houve mudanças depois da eleição do Rio de Janeiro à sede dos JO/PO 2016. Ele explicou que, paulatinamente, o PELC está sofrendo qualificações que já eram previstas antes mesmo dessa eleição e complementou, dizendo que "a tendência já era de ampliação, sempre, de implantação dos núcleos e de investimento em parcerias intersetoriais." (AGENTE 3, 2013, s.d.). Quadro muito diferente do que os "policy makers" direcionam para as "policies" do esporte de rendimento.

Sobre o que está sendo feito a respeito dos legados para o esporte de lazer, podese ter um panorama através das entrevistas. O agente 1 (2013, s.p.) explica que a APO está tentando dimensionar um projeto de legado, mas que há muitos detalhes presentes na "policy arena”, pois "as ações estão acontecendo e a APO ainda está num período de tentar reunir os atores envolvidos para procurar fazer um mapeamento e um projeto único, o que não quer dizer que as ações vão começar a ser desenvolvidas agora, mas sim costuradas e potencializadas". Este agente ressaltou, ainda, que a tarefa da APO não 
é organizar nada e sim ter uma planilha de monitoramento para saber o que está funcionando ou não. Ele diz que, por isso, a APO "está fazendo o trabalho preliminar que é ver os compromissos que estão no DC e dizer: vamos lá". O entrevistado ainda comenta que "como a APO tem os mesmos interesses na realização dos jogos e essa é uma área que está bem potencializada junto ao ME, a APO entende que, talvez, o ME já esteja traçando essa possibilidade de ampliação, mas, de qualquer maneira, vai chegar o dia em que a APO vai conversar sobre isso também".

A respeito das propostas apresentadas, o agente 2 (2013, s.p.) comentou que as ações do PST e PELC ainda não "andaram”, mas que já haviam tido a notícia de que a SNELIS tinha "batido o martelo" e iria universalizar o PST nas cidades sedes da Copa do Mundo 2014. "Por conta do programa Olímpico, eles vão estender não só para as cidades sede das Olimpíadas, mas para as demais cidades do futebol". Ele comenta que o PST será também um legado da Copa e haverá um tempo de 2013 a 2016 para levar o programa a todas as escolas das capitais que sediarão os jogos. $\mathrm{O}$ entrevistado ainda explicou que a negociação do PELC está em andamento e que o secretário atual da SNELIS já estava querendo chamar a APO para visualizar como será essa ampliação e fomento do PELC em decorrência desse momento; o que, para ele "é muito bom, porque alguns programas do ME tiveram uma redução do seu fomento, que pode ser retomado no Governo Federal como legado Olímpico”. Também em relação ao PELC, ele disse que acompanha à distância o andamento da Rede CEDES, que não vê nenhum movimento mais amplo "da Rede pela Rede" e lembra que, se a provocação não vier do ME, poderia vir até mesmo dos agentes do campo acadêmico, ou seja, das universidades e da própria Rede CEDES. 
Sobre o assunto, o agente 3 (2013, s.p.) garantiu que ainda não há relação estabelecida entre representantes do PELC com nenhuma das entidades de controle dos legados. No entanto, comentou sobre um projeto em andamento referente à Copa, semelhante ao do PST, que visa implantar núcleos do programa Vida Saudável nas capitais-sede. Sobre o legado olímpico, disse que há um Grupo de Trabalho (GT) de legado para o esporte educacional, que se reúne periodicamente desde 2012 na sede do ME do RJ, mas que o esporte de lazer não foi incluído nas discussões. Fazem parte deste GT: a APO, as Secretarias de Esporte e de Educação Estaduais e Municipais do Rio de Janeiro e o ME. Recentemente, o MEC também havia sido chamado para unir-se ao Grupo de Trabalho.

Ainda referente ao PELC, o agente 1 (2013, s.p.) garantiu que as discussões se iniciarão, porque havia chegado o momento e porque, antes, estavam tratando de outras questões, mas disse ser necessário organizar os segmentos - papel da APO -, já que os interesses, bem como as diversas rugas existentes precisam ser atenuadas. $\mathrm{O}$ entrevistado explicou estes embates ocorridos, indicando a existência de uma forte tensão entre os agentes que trabalham o esporte educacional e os que trabalham o esporte de lazer, fator que em sua opinião dificulta uma reunião para uma mesma discussão. Sendo assim, pode-se verificar um atraso nessa "negociação" do PELC. A proposta era incrementar esse programa até 2016, e, no entanto, desde a eleição do Rio à sede dos $\mathrm{JO} / \mathrm{PO}$, o que se pode afirmar com certeza é que o número de núcleos do PELC diminuiu e a Rede CEDES sofreu um esfriamento até a presente data.

A respeito de outras ações, o agente 2 (2013, s.p.) afirmou que o MEC já cumpriu, em 2012, o que prometeu no DC para 2016 - mais de 400 milhões em construções de quadras esportivas em escolas com o Mais Educação -, beneficiando não 
só a Educação Física e o esporte escolar, mas também as comunidades que usam estes espaços em seus momentos de lazer. O agente 1 (2013, s.p.) confirmou a informação, dizendo que a ampliação do "Bolsa Atleta" e do "Mais Educação" aconteceram, e que, na verdade, as coisas estão andando, mas a APO ainda não parou para fazer a última etapa da policy cycle”, ou seja, o monitoramento e acompanhamento de todas estas ações.

Segundo o agente 2 (2013, s.p.), outro investimento real do MEC é o estabelecimento de um consórcio - CONRIO -, que foi demandado pelas instituições federais do RJ, para o qual o MEC deverá financiar programas de pesquisa e de extensão universitária, que acabam "caindo" nos programas que acontecem junto às comunidades, beneficiando, dessa forma, os programas de lazer. O entrevistado contou que já foram mapeados muitos programas do Município e também do Estado, no entanto, explica que “isso é só o início do trabalho, porque tem outros legados que estão amadurecendo e que estão na fase de negociação." (AGENTE 2, 2013, s.p.). Como exemplos, citou uma negociação de legados, com o apoio do UNICEF, voltados para a criança e o adolescente, visando tanto ao fomento da prática esportiva e do lazer, quanto à apropriação do direito ao esporte e uma relação que está se constituindo com a Secretaria Nacional de Direitos Humanos para trabalhar a proteção ao direito de praticar esporte com segurança.

Segundo as falas dos entrevistados da APO, pode-se perceber que o esporte de lazer deve ser beneficiado não só através do que foi anunciado no DC e nos CLs. Há outras vias e, com isso, possibilidades vão surgindo durante o processo de preparação e organização do evento. O agente 1 (2013, s.p.) alegou que se fosse analisar cada iniciativa que existe para o esporte, seria inconsequente sair dizendo "tem isso, tem 
aquilo", porque, no dia em que tudo estiver mapeado (papel da APO), poderá ser divulgado e dizer que "do contrário, é muito prematuro". Ele comenta que "é um trabalho muito interessante, mas que na APO o foco não é o esporte e sim os serviços públicos e o evento" e completa dizendo que "no ME o foco é o esporte", lembrando que tal instituição tem que dar conta de suas ações e a APO deve somente acompanhar o processo, “[...] a APO não é sobre todo mundo, ela é com todo mundo [...]”. É importante lembrar que, como o entrevistado destacou, é interessante que a sociedade faça as devidas cobranças sobre o legado social, pois, se não, a prioridade será dada realmente a outras questões. Ele comentou que o legado esportivo ainda não está na ordem do dia, porque é apenas um dos elementos e que não é só isso que está atualmente em jogo na arena política.

Nos aspectos relativos à documentação oficial, o agente 1 (2013, s.p.) explica que, por parte da APO, há elementos pontuais e de consumo interno que ainda não foram divulgadas. O entrevistado lembra que, no final do ano de 2013, será possível conseguir mais informações junto a esse órgão, pois neste ano estão conhecendo agentes e projetos. Aponta também que, nesse mesmo período, deverão ter um tipo de matriz de responsabilidades, onde aparecerão todas as propostas, encaminhamentos, como estão sendo dados, quem são os responsáveis e, a partir daí, se poderá ter a noção do que está sendo feito. Porém, tais questões são cenas para próximos capítulos...

\section{CONSIDERAÇÕES FINAIS}

A sociedade brasileira ainda é carente no que se refere à prática do esporte e do lazer, um direito social que acaba ficando à sombra de preocupações consideradas mais emergentes, como saúde, educação, transporte e segurança pública. É importante 
lembrar que essa área também necessita de políticas e programas que oportunizem sua prática, sobretudo, àqueles indivíduos que são privados desse direito por suas condições sociais. Com a realização dos $\mathrm{JO} / \mathrm{PO}$ no Brasil, abriu-se uma porta para que tais assuntos fossem tratados com maior atenção, colocando as ações da "policy arena" esportiva do país na berlinda. O DC e os CLs apresentam propostas, ou melhor, promessas, que dão uma sustentação para que se possa, finalmente, dar outro rumo ao esporte no país. No entanto, há vários pontos que colocam esses juramentos em xeque. Como por exemplo, a visível diminuição no número de núcleos PELC, de 2008 até agora, e/ou os altos recursos direcionados ao conjunto do PELC que, desde 2009, são quase que totalmente destinados à infraestrutura.

Como visto no decorrer do artigo, os olhares por enquanto estão voltados para as fases iniciais da "policy cycle", e referem-se, principalmente, às promessas de entrega de infraestrutura, à realização dos jogos e ao desenvolvimento do esporte de rendimento. Sem dúvida, as disputas e interações entre "polities" e "politics", no interior da arena esportiva, são as responsáveis pela situação apresentada na construção das "policies", já que, como afirma Frey (2000) e Mezzadri (2011), estes atos sempre deixarão suas marcas nos programas e projetos desenvolvidos pelos governantes.

As questões sobre o esporte de lazer vão sendo postergadas com a desculpa de que podem acontecer até 2016. Neste ponto, vale lembrar a fala do agente 1 (2013), quando adverte que os legados sociais podem aparecer só mais tarde. Entretanto, acredita-se que, se essas questões forem tratadas muito tarde, pode não haver tempo para serem submetidas a discussões, avaliações, detecção de problemas e correção dos mesmos; ou seja, a "policy cycle", de fundamental importância para as políticas públicas para o esporte de lazer, não se completa, colocando em risco o objetivo de responder 
todas as demandas sociais. $\mathrm{O}$ que se apresenta no atual momento histórico, final do ano de 2013 e início de 2014, é que o ciclo da política pública não vem se completando. O ponto mais preocupante é que sequer existe um apontamento se tais questões realmente se desdobram em ações concretas. Ainda é importante lembrar que, para que haja legado para o esporte de lazer, somente a implantação de programas para a população, sem um compromisso de longo prazo, não é suficiente. Cumprir as promessas contidas nos documentos apenas para o período que antecede os jogos, até sua realização, não significa ter um legado.

Quando uma cidade-sede é escolhida, o COI exige providências com vistas a garantir que o prometido na candidatura seja cumprido. A título de lembrança sobre essas exigências, podem-se citar as seguintes: a criação de uma lei específica para o período de preparação e realização dos $\mathrm{JO} / \mathrm{PO}$; a concepção da $\mathrm{APO}$ e a constituição da equipe que fará o OGI, antes, durante e depois dos Jogos. Nesse sentido, a pergunta mais pertinente seria a seguinte: o que acontece se as promessas não se cumprirem? Talvez seja fácil responder sobre as promessas de infraestrutura com prazos de entrega anteriores aos $\mathrm{JO} / \mathrm{PO}$, já que são as mais controladas, inclusive com inspeções periódicas. Mas, o que dizer sobre aquelas intangíveis, como por exemplo, o aumento da prática esportiva e de lazer e/ou a melhoria de programas esportivos?

A ideia é continuar fazendo esse acompanhamento das relações entre as propostas de esporte de lazer, inseridas no DC e nos CLs Rio 2016, com o planejamento, ações e financiamento da área, durante todo o processo de construção e entrega dos legados esportivos, pois, dessa forma, existirá uma contribuição para o aumento do conhecimento sobre todo o ciclo da "policy cycle", o que, como alegaram Ham e Hill (1993), pode proporcionar a melhoria das informações disponibilizadas aos 
"policy makers". Acredita-se que, com essa postura de acompanhamento, o Brasil possa se destacar positivamente entre outros países-sede, no que se refere ao legado para o esporte participativo.

\section{REFERÊNCIAS}

ATHAYDE, P. et. al. O agendamento dos Jogos Rio 2016: Temas e termos para debate. Pensar a Prática, Goiânia, v. 16, n. 3, p. 619-955, jul./set. 2013

AGENTE 1. Entrevista: Autoridade Pública Olímpica [jul. 2013]. Rio de Janeiro, 2013. Arquivo original em .mp3 (60 min.)

AGENTE 2. Entrevista: Autoridade Pública Olímpica [jul. 2013]. Rio de Janeiro, 2013. Arquivo original em .mp3 (60 min.).

AGENTE 3. Entrevista: Secretaria Nacional de Esporte, Lazer e Inclusão Social Ministério do Esporte [ago. 2013].. Brasília, 2013. Arquivo original em .mp3 (60 min.).

BARDIN, L. Análise de Conteúdo. Lisboa: Edições 70, 2006.

BRASIL. Plano plurianual 2008-2011: projeto de lei/Ministério do Planejamento, Orçamento e Gestão, Secretaria de Planejamento e Investimentos Estratégicos. Brasília: Ministério Público, 2007.

2008.

. Esporte e Lazer da Cidade - PELC: Catálogo 2007-2008. Brasília: ME,

. Caderno de Legado Brasil. Brasília: ME, 2009a.

Caderno de Legado Social. Brasília: ME, 2009b.

. Plano plurianual 2012-2015: projeto de lei/Ministério do Planejamento, Orçamento e Gestão, Secretaria de Planejamento e Investimentos Estratégicos. Brasília: Ministério Público, 2011.

Prestação de Contas da Presidenta da República/2011. Relatório Sobre os Orçamentos e Atuação Governamental - Balanço Geral da União. Brasília: CGU, 2012.

Prestação de Contas da Presidenta da República/2012. Relatório Sobre os Orçamentos e Atuação Governamental - Balanço Geral da União. Brasília: CGU, 2013.

COMITÊ RIO 2016. Rio 2016: cidade candidata. Dossiê de candidatura. Rio de Janeiro: COB, 2009. 
DEUBEL, A. N. R. Políticas Públicas: formulación, implementación e evolución. Bogotá, 2006.

DONNELLY, P. Opportunity Knocks!: Increasing Sport Participation in Canada as a Result of Success at the Vancouver Olympics. Centre for Sport Policy Studies Position Paper Series, n. 2. Toronto: Centre for Sport Policy Studies, Faculty of Kinesiology and Physical Education, University of Toronto. 2008.

DYE, T. R. Policy analysis. Alabama: University of Alabama Press, 1976.

FILGUEIRA, J. C. M. Importância dos Legados de Megaeventos Esportivos para a Política Nacional do Esporte: Cidade, Cidadania e Direitos dos Cidadãos. In: RODRIGUES, R. P. et. al. (Org.). Legados de Megaeventos Esportivos. Brasília: ME, 2008, p. 65-73.

FREY, K. Análise de políticas públicas: Algumas reflexões e suas implicações para a situação brasileira. Cadernos de Pesquisa, n.18, setembro. PPGSP/UFSC. 2000.

GOMES, C.; PINTO, L. O lazer no Brasil: analisando práticas culturais cotidianas, acadêmicas e políticas. In: GOMES, C. et al. (Org.). Lazer na América Latina/Tiempo libre, ócio y recreación en Latinoamérica. Belo Horizonte: Editora UFMG, 2009, p. 67-122.

HAM, C. E HILL, M. The policy process in the modern capitalist state. London: Harvester Wheatsheaf, 1993.

JOVCHELOVICHT, S.; BAUER, M. W. Entrevista Narrativa. In: BAUER, M. W.; GASKELL, G. (ed.). Pesquisa qualitativa com texto, imagem e som: um manual prático. Petrópolis, Vozes, 2002. p. 90- 113.

MASCARENHAS, F. Megaeventos esportivos e Educação Física: alerta de tsunami. Movimento, Porto Alegre, v. 18, n. 01, p. 39-67, jan/mar de 2012.

MENICUCCI, T. Políticas de esporte e lazer: o estado da arte e um objeto em construção. In: ISAYAMA, H. F.; LINHALES, M. A. (Org.). Avaliação de políticas e políticas de avaliação: questões para o esporte e o lazer. Belo Horizonte: Editora UFMG, 2008, 179-202.

MEZZADRI, F. M. Políticas Públicas para o Esporte e lazer: teorias e conceitos. In: MOTTA, A; TERRA, R. (Org.). Esporte, Lazer e políticas públicas na região dos Lagos. Rio de Janeiro: iVentura, 2011, p. 89-102.

OURIQUES, N. Olimpíada 2016 - O desenvolvimento do subdesenvolvimento. Motrivivência, v. 21, n. 32/33, p. 126-155, Jun-Dez./2009.

REIS, A C.; SOUSA-MAST, F. R. Rio 2016 and Sport Legacies. The legacies of the Olympic Games for youth at-risk in Rio de Janeiro. 50 folhas. Postgraduate research grant programme 2012. Olympic Studies Centre, International Olympic Committee. Final Research Report, 2012. 
RIO 2016. Rio 2016 e COPPE formalizam contrato para produção do estudo de impacto dos jogos. Disponível em: <http://rio2016.org/noticias/noticias/rio-2016-ecoppe-formalizam-contrato-para-producao-do-estudo-de-impacto-dos-jogos $>$ Acesso em: 15 jul. 2013.

SOUSA, E. S. et. al. Sistema de monitoramento \& avaliação dos programas Esporte e Lazer da Cidade e Segundo Tempo do Ministério do Esporte. Belo Horizonte: O Lutador, 2010.

SOUZA, C. Políticas Públicas: uma revisão da literatura. Sociologias, Porto Alegre, v. 8 , n. 16, jul/dez 2006, p. 20-45.

SOUZA, A. P. P. et. al. Megaeventos esportivos: competições esportivas ou políticas/econômicas? Motrivivência, v. 25, n. 41, p. 101-114 Dez./2013

SOUZA, D. L.; PAPPOUS, S. Legados esportivos de megaeventos esportivos: uma revisão da literatura. Motrivivência, v.25,n. 41, p. 42-56 Dez./2013.

StAREPRAVO, F. A. Políticas Públicas de Esporte e Lazer no Brasil: Aproximações, intersecções, rupturas e distanciamentos entre os subcampos políticos/burocráticos e científico/acadêmico. Tese (Doutorado) - defendida na UFPR, 2011.

VILlANO, B. et al. Seminário "Gestão de Legados de Megaeventos Esportivos": Pontos de Convergência. In: RODRIGUES, R. P. et al. (Org.). Legados de Megaeventos Esportivos. Brasília: Ministério do Esporte, 2008. p. 47-50.

\section{Endereço dos Autores:}

Katiuscia Mello Figuerôa

R. Rio Jari, 800 - Bairro Alto

Curitiba - PR - CEP: 82840-210

Endereço Eletrônico: ktmello@gmail.com

Fernando Marinho Mezzadri

Rua Bandeirantes Dias Cortes. 123 casa 2 - Jd Social

Curitiba - PR - CEP: 82530-120

Endereço Eletrônico: fmezzadri@uol.com.br

Marcelo Moraes e Silva

Rua Martin Afonso 226 ap. 3A

Curitiba - PR - CEP: 80410-060

Endereço Eletrônico: moraes_marc@yahoo.com.br 